\title{
Biomassa e nutrientes em povoamento de Eucalyptus urograndis na Serra do Sudeste-RS
}

\author{
Biomass and nutrients in Eucalyptus urograndis stands in \\ southeastern Mountain Range-RS
}

\author{
Márcio Viera $^{{ }^{*}}$; Darlan Michel Bonacina ${ }^{2}$; Mauro Valdir Schumacher ${ }^{3}$; Francine \\ Neves Cali1 ${ }^{4}$; Marcos Vinicius Winckler Caldeira ${ }^{5}$; Luciano Farinha Watzlawick ${ }^{6}$
}

\section{Resumo}

Objetivou-se quantificar a biomassa e os nutrientes, em povoamentos de Eucalyptus urograndis, aos 18 meses de idade na serra do sudeste, Piratini-RS. Alocaram-se 24 parcelas de $15,0 \mathrm{~m}$ x 22,5 m, após abateu-se uma árvore em cada, sendo esta, a que possuía o diâmetro médio a altura do peito. A árvore foi fracionada nos seguintes componentes da biomassa acima do solo: madeira, casca, galhos e folhas. A biomassa total foi $18,5 \mathrm{Mg} \mathrm{ha}^{-1}$, sendo a madeira a fração que apresentou maior percentual $(37,0$ $\%)$, seguida pelos galhos $(34,2 \%)$, folhas $(21,3 \%)$ e casca $(7,6 \%)$. As folhas apresentaram as maiores concentrações de nutrientes, sendo estatisticamente superior as demais frações $(p<0,05)$, com exceção ao $\mathrm{Ca}, \mathrm{Mg}$ e $\mathrm{B}$. Para os macronutrientes, a magnitude de acumulação foi: $\mathrm{Ca}>\mathrm{N}>\mathrm{K}>\mathrm{Mg}>\mathrm{P}>\mathrm{S}$ e $\mathrm{Mn}>\mathrm{Fe}>\mathrm{B}>\mathrm{Zn}>\mathrm{Cu}$, para os micronutrientes. A maior quantidade de nutrientes estava contida no componente folhas, devido a sua maior concentração de nutrientes, com exceção ao $\mathrm{Ca}, \mathrm{Mg}$ e $\mathrm{Cu}$ que estão alocados em maiores quantidades nos galhos.

Palavras-chave: Nutrição florestal, produção florestal, nutrientes

\begin{abstract}
This study had as objective to quantify biomass and nutrients, in an 18 months Eucalyptus urograndis stand in southeastern mountain range, Piratini-RS. Twenty-four (24) plots $(15.0 \mathrm{~m} \mathrm{x} 22.5 \mathrm{~m})$ were allocated; after that, one tree (with diameter at breast height) was felled in each plot. The tree was fractionated in the following fractions of above ground biomass: wood, bark, branches and leaves. Total biomass was $18.5 \mathrm{Mg} \mathrm{ha}^{-1}$, being the wood the fraction with highest biomass (37\%), followed by branches $(34.2 \%)$, leaves $(21.3 \%)$ and bark $(7.6 \%)$. Leaves showed highest nutrients concentrations, being statistically superior to other fractions $(\mathrm{p}<0.05)$, excepted for $\mathrm{Ca}, \mathrm{Mg}$ and $\mathrm{B}$. For macronutrients, the accumulation magnitude was $\mathrm{Ca}>\mathrm{N}>\mathrm{K}>\mathrm{Mg}>\mathrm{P}>\mathrm{S}$, and for micronutrients was $\mathrm{Mn}>\mathrm{Fe}>\mathrm{B}$ $>\mathrm{Zn}>\mathrm{Cu}$. Highest amount of nutrients is contained on leaves component, due to the highest nutrients concentration, excepted for $\mathrm{Ca}, \mathrm{Mg}$ and $\mathrm{Cu}$ that are located in large quantities in the branches.
\end{abstract}

Key words: Forestry nutrition, forestry production, nutrients

\footnotetext{
${ }^{1}$ Eng $^{\text {o }}$ Florestal, Dr. Prof. Adjunto do Depto. Multidisciplinar, Unidade Descentralizada de Educação Superior, Universidade Federal de Santa Maria, UFSM, Silveira Martins, RS. E-mail: vieraflorestal@yahoo.com.br

${ }^{2}$ Eng $^{\mathrm{o}}$ Florestal, Centro de Ciências Rurais, UFSM, Santa Maria, RS. E-mail: darlanbonacina@yahoo.com.br

${ }^{3}$ Eng $^{\mathbf{o}}$ Florestal, Dr. nat. techn., Prof. Associado do Dept ${ }^{\mathrm{o}}$ de Ciências Florestais, Centro de Ciências Rurais, UFSM, Santa Maria, RS. Bolsista CNPq. E-mail: mvschumacher@gmail.com

${ }^{4}$ Eng $^{\mathrm{a}}$ Florestal, Dr ${ }^{\mathrm{a}}$. Prof ${ }^{\mathrm{a}}$ da Universidade Federal de Goiás, UFG, Escola de Agronomia e Engenharia de Alimentos, Goiânia, GO.E-mail: francine.calil@terra.com.br

${ }^{5}$ Eng $^{\text {o }}$ Florestal, Dept ${ }^{\mathrm{o}}$ de Engenharia Florestal, Centro de Ciências Agrárias, Universidade Federal do Espírito Santo, UFES, Alegre, ES. E-mail: caldeiaramv@pq.cnpq.br

${ }^{6}$ Eng $^{\text {o }}$ Florestal, Setor de Ciências Agrárias e Ambientais, Universidade Estadual do Centro-Oeste, UNICENTRO, Guarapuava, PR. E-mail: luciano.watzlawick@pq.cnpq.br

* Autor para correspondência
} 


\section{Introdução}

O primeiro registro da presença do eucalipto no Brasil é de 1825, como planta ornamental, mas o aproveitamento econômico teve início em 1903, com a produção de dormentes ferroviários e lenha para movimentar as locomotivas da Companhia Paulista de Estradas de Ferro (HASSE, 2006). Foi nos anos 50 que a importância econômica do eucalipto ganhou impulso no Brasil, com o início de sua utilização como matéria-prima para a produção de celulose e papel (ABECEL, 2004).

Os plantios florestais de eucalipto têm evoluído rapidamente nos últimos anos, com a adoção de práticas sustentáveis de manejo florestal, que hoje, inclusive, são objeto de certificação independente. Um dos grandes feitos da pesquisa florestal no Brasil foi o desenvolvimento de uma tecnologia silvicultural de florestas plantadas, reconhecida no mundo todo (SILVA, 2005).

Além do mais, um dos principais benefícios do cultivo dos eucaliptos, um bem natural renovável, é oferecer alternativa para o suprimento de madeira, diminuindo a pressão sobre as florestas nativas. Pois mesmo que estas pudessem ser utilizadas de forma sustentável, não seriam suficientes para atender a crescente demanda de madeira, devido às dificuldades técnicas de manejo para que se obtenha a produtividade compatível com as necessidades das empresas.

Desta forma, faz-se importante a realização de estudos sobre essa espécie de tão grande valor econômico, principalmente no que diz respeito às práticas silviculturais aplicadas nesses povoamentos. Com a implantação destes, em áreas com baixo potencial produtivo, como é o caso da região sul do estado do Rio Grande do Sul (Serra do Sudeste e Campanha), onde há pouco estudo sobre o desenvolvimento da espécie no local, é de suma importância que se tenha o conhecimento técnico - cientifico em relação às características nutricionais do sistema solo-planta, para aumentar a produtividade destes povoamentos e mantê-la para rotações futuras.

Para obter-se esses conhecimentos, é necessário entendermos a nutrição florestal, principalmente no que se refere ao adequado suprimento de nutrientes as plantas, que segundo Silveira, Higashi e Moreira (2000), a falta ou excesso de um ou mais nutrientes provoca anormalidades nas árvores, diminuindo sua produtividade. Para isso, é necessário o estudo da biomassa e nutrientes nela contido. Desta maneira, é possível entender os processos necessários e potenciais ao máximo desenvolvimento fisiológico de uma planta.

A quantificação da biomassa e de nutrientes em qualquer forma de ecossistema florestal é de fundamental importância para que se conheça a dinâmica dos nutrientes nos diversos compartimentos do ecossistema, podendo-se assim, encontrar indicadores de possíveis impactos que algumas técnicas silviculturais podem causar (REIS; BARROS, 1990; CALDEIRA et al., 2008).

Devido a isso, objetivou-se por meio deste estudo quantificar a biomassa e os nutrientes nos diferentes compartimentos do Eucalyptus urograndis, aos 18 meses de idade na Serra do Sudeste, RS.

\section{Material e Métodos}

\section{Caracterização da área de estudo}

O estudo foi realizado em um povoamento de Eucalyptus urograndis aos 18 meses de idade, localizado no município de Piratini, região da Serra do Sudeste, RS (Figura 1), situado no entorno das coordenadas geográficas de $31^{\circ} 20^{`}$ de latitude Sul e $53^{\circ} 10^{`}$ de longitude Oeste, numa altitude média de $350 \mathrm{~m}$ em relação ao nível do mar. O município de Piratini localiza-se no sul do Estado do Rio Grande do Sul, na região fisiográfica da Serra do Sudeste. 
Figura 1. Localização do município de Piratini, Serra do Sudeste, Rio Grande do Sul.

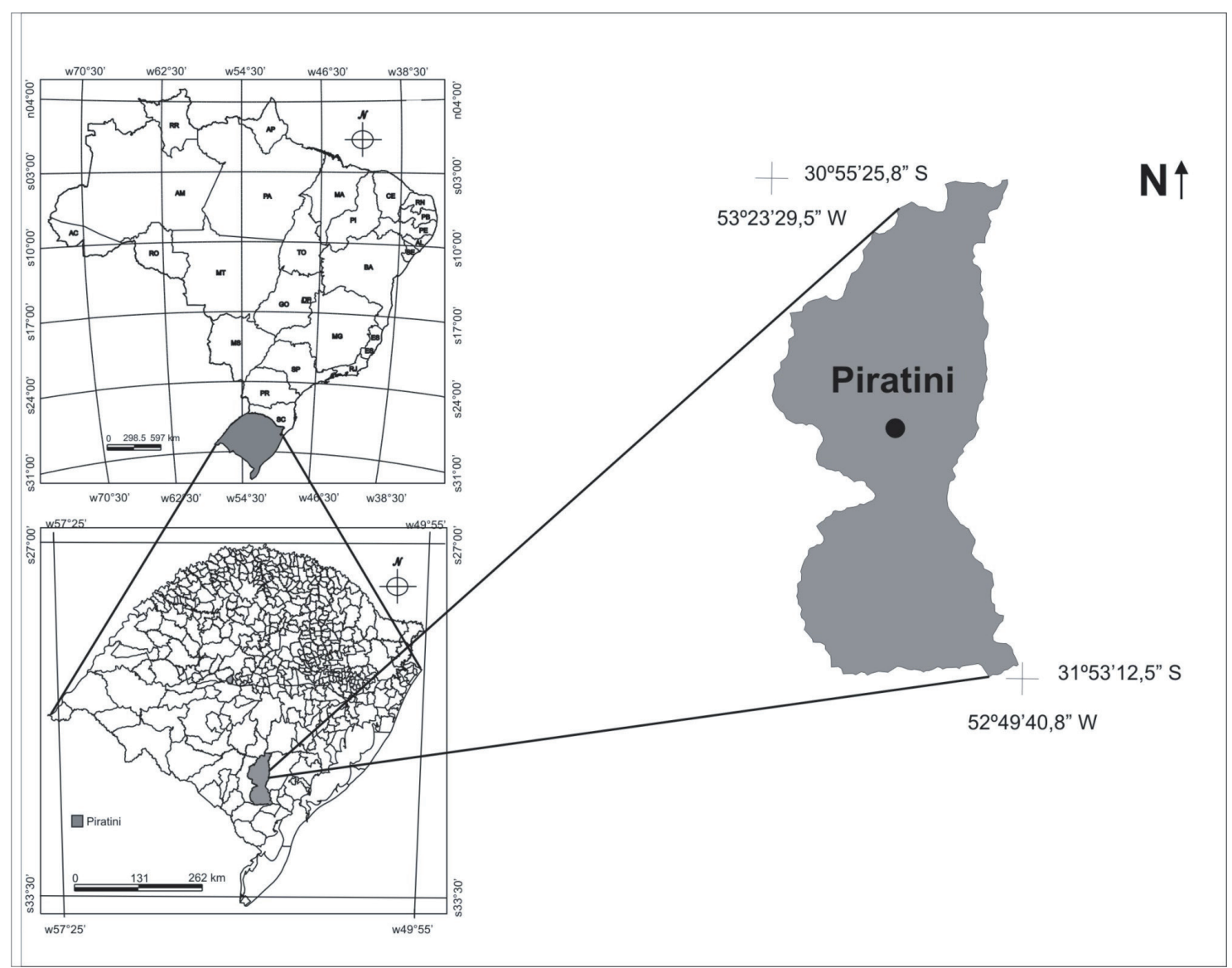

Fonte: Elaboração dos autores.

Segundo a classificação climática de Köppen, o tipo de clima fundamental predominante é o Cfa (subtropical úmido), a precipitação média anual na região é de $1.364 \mathrm{~mm}$. A temperatura média anual é de aproximadamente $17,5^{\circ} \mathrm{C}$, sendo que a média das máximas é de $23,5^{\circ} \mathrm{C}$ e a média das temperaturas mínimas é de $12,3^{\circ} \mathrm{C}$ (MORENO, 1961).

$\mathrm{O}$ solo da região, em sua maioria pertence à unidade de mapeamento Pinheiro Machado, sendo classificados como Neossolo Litólico Distrófico típico e Neossolo Regolítico Disto-úmbrico típico e cujo os atributos químicos, determinados segundo Tedesco et al. (1995), são apresentados na Tabela 1. Os Neossolos Litólicos e Regolíticos são solos rasos ou poucos profundos, novos, poucos desenvolvidos e encontrados nas mais diversas situações de relevo e drenagem. O perfil representativo da unidade apresenta um horizonte A assentado sobre a rocha totalmente alterada ou parcialmente alterada (horizonte $\mathrm{C}$ ) ou a rocha inalterada (camada $\mathrm{R}$ ) (STRECK et al., 2008).

A vegetação nesses solos é característica da Serra do Sudeste, formada pela mata subtropical arbustiva, localizadas principalmente ao entorno de córregos de água (mata ciliar) com formação e distribuição muito irregular apresentando várias espécies, especialmente Mirtáceas e pelo campo nativo nas demais áreas (RAMBO, 2005). 
Tabela 1. Atributos químicos do solo sob povoamento de Eucalyptus urograndis no município de Piratini-RS.

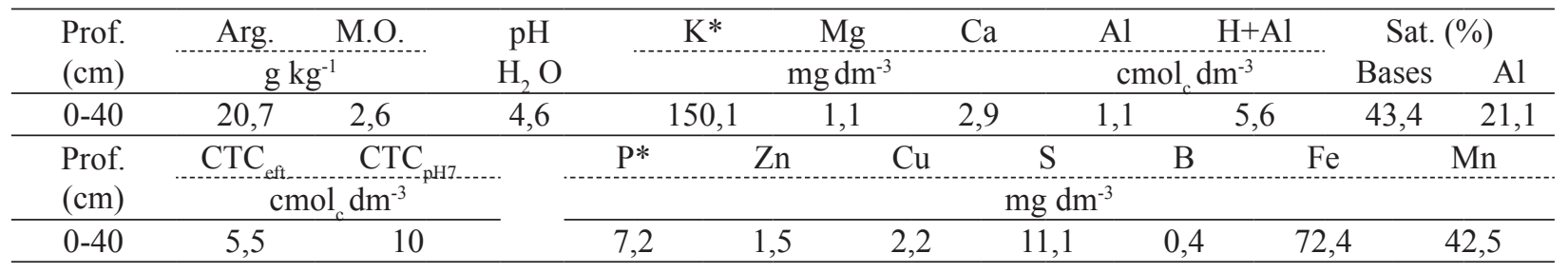

* Extrator Melich I.

Fonte: Elaboração dos autores.

\section{Metodologia de estudo}

A implantação do povoamento de eucalipto foi realizada entre setembro e outubro de 2005, em solo com preparo mínimo na linha de plantio, num espaçamento de $3,0 \mathrm{~m}$ x 2,25 m. Por ocasião do plantio, efetuou-se adubação de base, utilizando-se $270 \mathrm{~kg} \mathrm{ha}^{-1}$ de NPK (06:30:06) + 0,1\% de B + 0,5\% de $\mathrm{Cu}$. Aos dois e três meses do plantio, realizou-se a adubação de cobertura, utilizando-se $146,6 \mathrm{~kg} \mathrm{ha}^{-1}$ de NPK $(15: 03: 15)+0,7 \%$ de B + 7\% de S. Entre o $6^{\circ}$ e $9^{\circ}$ mês de idade do povoamento, efetuou-se a segunda adubação de cobertura, utilizando-se em torno de $200 \mathrm{~kg} \mathrm{ha}^{-1}$ de Sulfato de amônia $+1 \%$ de B.

A área de estudo abrangeu 1.167 ha. Sendo primeiramente realizado um inventário florestal (SOARES; PAULA NETO; SOUZA, 2006), através da alocação de 24 parcelas amostrais com dimensões

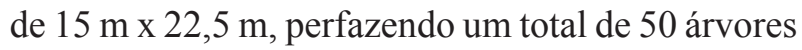
avaliadas em cada parcela. Essa avaliação procedeuse através da medição do diâmetro a altura do peito (DAP) com o auxilio de uma fita diamétrica. Após abateu-se uma árvore em cada parcela, sendo esta, a que possuía o diâmetro médio, baseado na média diamétrica obtida na medição das 50 árvores, totalizando 24 árvores abatidas em toda a área de estudo.

Uma vez abatida à árvore média de cada parcela, a mesma era separada nas seguintes frações formadoras da biomassa acima do solo: madeira (lenho correspondente a porção compreendida entre o nível do solo e o ápice da árvore), casca, galhos e folhas. Para cada fração foi quantificada a massa úmida em balança digital de precisão (1 g), com posterior amostragem da mesma.

Em relação à madeira e a casca, a amostragem procedeu-se da seguinte maneira: distribuiu-se 3 pontos de amostragem no decorrer do comprimento total do fuste, nas posições medianas das secções resultantes da divisão em 3 partes iguais do mesmo. $\mathrm{Na}$ fração galhos, amostrou-se de forma aleatória todo o componente, desde galhos finos a grossos localizados em toda a copa e para a fração folhas procedeu-se uma amostragem aleatória de todo o componente.

Após a amostragem de cada componente, o que correspondia a $50 \mathrm{~g}$ de massaúmida, os mesmos foram colocados em embalagens de papel, devidamente identificados e posteriormente encaminhados ao laboratório de Ecologia Florestal do Departamento de Ciências Florestais da Universidade Federal de Santa Maria, onde foram postas para secar em estufa de circulação e renovação de ar por 72 horas, sendo então determinada à massa seca em balança digital de precisão $(0,01 \mathrm{~g})$. As amostras, posteriormente, foram moídas em moinho tipo Wiley com peneira de 30 mesh e analisadas quanto os teores de nitrogênio, pelo método Kjeldahl; fósforo e boro por espectrometria visível; potássio por fotometria de chama; enxofre por turbidimetria; e cálcio, magnésio, cobre, ferro, manganês e zinco por espectrofotometria de absorção atômica; segundo Tedesco et al. (1995). 
A quantificação da biomassa foi realizada com base na biomassa média seca de cada componente e estimada com base nas áreas amostradas. Para o cálculo da quantidade de nutrientes nos compartimentos do eucalipto, foi efetuada por meio do produto da concentração média de nutrientes pela biomassa. As análises estatísticas foram realizadas com o auxilio do programa estatístico ASSISTAT versão 7.5 beta (SILVA, 2008) ao nível de 5\% de probabilidade de erro. O teste de Tukey foi utilizado para a comparação de médias.

\section{Resultados e Discussão}

\section{Biomassa acima do solo}

A biomassa acima do solo do eucalipto foi 18,5 $\mathrm{Mg} \mathrm{ha} \mathrm{h}^{-1}$, sendo a madeira a fração que apresentou maior biomassa (37,0\% do total), seguido de galhos $(34,2 \%)$, folhas $(21,3 \%)$ e casca $(7,6 \%)$ (Tabela 2). $\mathrm{O}$ diâmetro médio a altura do peito (DAP) foi de $6,7 \mathrm{~cm}$ e a altura média foi de $7,0 \mathrm{~m}$, sendo o volume total com casca de $21,2 \mathrm{~m}^{3} \mathrm{ha}^{-1}$. A biomassa total encontrada nesse estudo é superior ao esperado para a espécie, visto que, Viera (2007) avaliando a mesma espécie, com a mesma idade, implantada em solos similares obteve valores variando entre 9,65 e 16,0 $\mathrm{Mg} \mathrm{ha}^{-1}$.

Estudos realizados em duas áreas diferentes com Eucalyptus grandis, em região de Cerrado, Reis et al. (1985) encontraram uma biomassa acima do solo de 9,6 e 11,6 $\mathrm{Mg} \mathrm{ha}^{-1}$ aos 15 e 21 meses de idade, respectivamente. Em um povoamento de Eucalyptus saligna, aos quatro anos de idade, Schumacher e Caldeira (2004) encontraram uma produção de biomassa total de 79,6 Mg ha ${ }^{-1}$. Padrão similar foi observado por Schumacher e Caldeira (2001) em um povoamento de Eucalyptus globulus subespécie maidenii, também aos 4 anos de idade, onde a biomassa quantificada acima do solo foi de 83,2 $\mathrm{Mg} \mathrm{ha}^{-1}$.

Tabela 2. Características dendrométricas de diâmetro a altura do peito (DAP), altura (h) e volume (V) e biomassa dos compartimentos do Eucalyptus urograndis, aos 18 meses, no município de Piratini-RS.

\begin{tabular}{|c|c|c|c|c|c|c|c|c|}
\hline \multirow{2}{*}{ Variável } & \multirow{2}{*}{$\begin{array}{l}\text { DAP } \\
(\mathrm{cm})\end{array}$} & \multirow{2}{*}{$\begin{array}{c}\mathrm{h} \\
(\mathrm{m})\end{array}$} & \multirow{2}{*}{$\begin{array}{c}\mathrm{V} \\
\left(\mathrm{m}^{3} \mathrm{ha}^{-1}\right)\end{array}$} & \multicolumn{5}{|c|}{ Biomassa $\left(\mathrm{kg} \mathrm{ha}^{-1}\right)$} \\
\hline & & & & Madeira & Casca & Galhos & Folhas & Total \\
\hline Média & 6,7 & 7,0 & 21,2 & $\begin{array}{l}6.843,7 \\
(37,0)^{*}\end{array}$ & $\begin{array}{c}1.402,3 \\
(7,6)\end{array}$ & $\begin{array}{c}6.327,7 \\
(34,2)\end{array}$ & $\begin{array}{c}3.943,0 \\
(21,3)\end{array}$ & $\begin{array}{c}18.516,6 \\
(100,0) \\
\end{array}$ \\
\hline Desvpad $( \pm)$ & 0,8 & 0,7 & 6,6 & $1.766,4$ & 357,4 & $2.146,5$ & $1.197,3$ & $4.981,5$ \\
\hline
\end{tabular}

* Valores entre parênteses, referem-se à porcentagem que cada componente contribui para a formação da biomassa total acima do solo.

Fonte: Elaboração dos autores.

A distribuição dos componentes em ordem decrescente foi à seguinte: madeira $>$ galhos $>$ folhas $>$ casca. Andrae e Krapfenbauer (1979), analisando a distribuição da biomassa nos diferentes componentes arbóreos em povoamento de Eucalyptus saligna aos quatro anos de idade, implantado no município de Santa Maria-RS, observaram a mesma magnitude. Os compartimentos madeira e casca, juntas, foram responsáveis por cerca de $45 \%$ da biomassa total.

Os mesmos valores de biomassa do fuste (madeira
+ casca), encontrados neste estudo, em relação à da copa (folhas + galhos) é justificado pelo estado de juvenilidade em que o povoamento se encontra (18 meses de idade), onde devido ao dossel não estar completamente fechado, permite a passagem de luminosidade, favorecendo o crescimento de galhos e folhas da base ao topo do fuste. Esses valores devem-se inverter com o crescimento das árvores e conseqüente fechamento do dossel e senescência da parte média-inferior da copa, que deixara de ser 
uma fonte consumidora de fotoassimilados, sendo estes, a partir de então, acumulados em parte na biomassa do fuste (VIERA, 2007).

Análise semelhante também foi realizada por Schumacher (1992), afirmando durante a fase inicial de desenvolvimento de uma floresta, boa parte dos carboidratos é canalizada para a produção de biomassa da copa, mas com o passar do tempo, quando as copas iniciam a competir entre si por espaço, a produção relativa do tronco aumenta e as de folhas e ramos diminui gradativamente.

Estudando o acúmulo de biomassa em uma seqüência de idade de Eucalyptus grandis plantado no cerrado, Reis et al. (1985) observaram que na fase inicial de desenvolvimento do povoamento (15 meses de idade), a biomassa contida nos componentes madeira + casca é inferior a $45 \%$ do total da biomassa aérea. Porém, com o passar do tempo, esses componentes iniciaram uma crescente elevação na contribuição, até atingir mais de $85 \%$ da biomassa aérea total aos 73 meses de idade.

Poggiani et al. (1983) e Pereira et al. (1984) analisando povoamentos de Eucalyptus saligna, aos 8 e 9 anos de idade, respectivamente, verificaram que em média $85 \%$ da biomassa aérea encontravase no fuste (madeira + casca) e o restante na copa. Santana, Barros e Neves (1999), encontraram valores superiores em relação aos encontrados pelos autores citados anteriormente, variando entre $88 \mathrm{e}$ $92 \%$ a biomassa de fuste em diferentes procedências de Eucalyptus saligna e Eucalyptus grandis em 5 sítios diferentes aos 6,5 anos de idade, no estado de São Paulo.

\section{Nutrientes na biomassa}

Em termos gerais, o componente com maior teor de nutrientes é a fração folhas e o com menor concentração a madeira, sendo que as frações galhos e casca possuem valores intermediários (Tabelas 3 e 4). Essa tendência que a maioria dos nutrientes tem de concentrarem-se nas estruturas mais novas da planta, devem-se às folhas possuírem maior atividade metabólica. Além disso, nestas regiões se encontram a maioria das células vivas, responsáveis pela fotossíntese e transpiração (FERRI, 1985).

Essa mesma tendência, de maior teor de nutrientes nas folhas, foi encontrada por Viera (2007), em povoamentos de Eucalyptus urograndis e E. saligna no município de Pinheiro MachadoRS; por La Torraca, Haag e Migliorini (1984), em um povoamento de Pinus elliotii var. elliotti, em um Latossolo Vermelho na região de Agudos-SP; por Bellote (1979), em Eucalyptus grandis Hill exMaiden em Mogi Guaçu - SP; e, por Pereira et al. (2000), em Acacia mearnsii De Wild no município de Butiá-RS.

$\mathrm{O}$ teor de $\mathrm{N}$, bem superior nas folhas em comparação aos demais componentes, deve-se ao fato deste elemento participar da maioria das reações de metabolismo de compostos (aminoácidos, proteínas, aminas, amidas, vitaminas, entre outros), as quais têm seu sítio de ocorrência principal nas folhas, em virtude da ocorrência da fotossíntese (MALAVOLTA, 1985).

Para os nutrientes $\mathrm{Ca}$ e $\mathrm{Mg}$ os maiores teores foram constatados no compartimento casca. De forma concordante Schumacher e Poggiani (1993), analisando povoamentos de E. camaldulensis, E. grandis e E. torelliana com 9, 9 e 12 anos de idade, respectivamente, observaram maiores teores de $\mathrm{Ca}$ e $\mathrm{Mg}$ na casca.

A exemplo do nitrogênio, segundo Ferri (1985), o fósforo tem ampla mobilidade dentro da planta e, com isso, ele tende a se concentrar nos órgãos mais novos, no caso deste estudo, no componente folhas. No caso do Ca, esse mesmo autor salienta que, a sua imobilidade no floema, nas plantas, poderia explicar a sua concentração elevada na fração casca, assim como o fato de o elemento ser componente estrutural, fazendo parte da lamela média de membrana celular. 
Tabela 3. Teores de macronutrientes na biomassa de Eucalyptus urograndis aos 18 meses de idade, no município de Piratini-RS.

\begin{tabular}{ccccccc}
\hline \multirow{2}{*}{ Componentes } & \multicolumn{7}{c}{ Macronutrientes $\left(\mathrm{g} \mathrm{kg}^{-1}\right)$} \\
\cline { 2 - 7 } & $\mathrm{N}$ & $\mathrm{P}$ & $\mathrm{K}$ & $\mathrm{Ca}$ & $\mathrm{Mg}$ & $\mathrm{S}$ \\
\hline \multirow{2}{*}{ Madeira } & $2,2 \mathrm{~b}^{\mathrm{b}}$ & $0,30^{\mathrm{b}}$ & $3,67^{\mathrm{c}}$ & $2,05^{\mathrm{c}}$ & $0,48^{\mathrm{c}}$ & $0,22^{\mathrm{b}}$ \\
& $( \pm 0,42)^{* *}$ & $( \pm 0,04)$ & $( \pm 1,04)$ & $( \pm 0,88)$ & $( \pm 0,12)$ & $( \pm 0,06)$ \\
\multirow{2}{*}{ Casca } & $4,60^{\mathrm{b}}$ & $0,58^{\mathrm{b}}$ & $7,03^{\mathrm{b}}$ & $19,88^{\mathrm{a}}$ & $2,79^{\mathrm{a}}$ & $0,32^{\mathrm{b}}$ \\
& $( \pm 0,58)$ & $( \pm 0,19)$ & $( \pm 2,07)$ & $( \pm 5,81)$ & $( \pm 0,48)$ & $( \pm 0,05)$ \\
\multirow{2}{*}{ Galhos } & $3,61^{\mathrm{b}}$ & $0,48^{\mathrm{b}}$ & $5,71^{\mathrm{bc}}$ & $14,19^{\mathrm{b}}$ & $1,65^{\mathrm{b}}$ & $0,26^{\mathrm{b}}$ \\
& $( \pm 0,61)$ & $( \pm 0,15)$ & $( \pm 3,22)$ & $( \pm 5,85)$ & $( \pm 0,27)$ & $( \pm 0,08)$ \\
\multirow{2}{*}{ Folhas } & $27,08^{\mathrm{a}}$ & $1,72^{\mathrm{a}}$ & $10,91^{\mathrm{a}}$ & $10,55^{\mathrm{b}}$ & $2,66^{\mathrm{a}}$ & $1,24^{\mathrm{a}}$ \\
& $( \pm 4,72)$ & $( \pm 0,35)$ & $( \pm 1,96)$ & $( \pm 1,37)$ & $( \pm 0,36)$ & $( \pm 0,20)$ \\
\hline CV $(\%)$ & 116,46 & 78,53 & 49,25 & 72,67 & 53,12 & 87,64 \\
\hline
\end{tabular}

* Médias seguidas pela mesma letra na vertical, não diferem entre si pelo Teste de Tukey a 5\% de probabilidade de erro. **Valores entre parênteses, referem-se ao desvio padrão da média do nutriente em cada componente.

Fonte: Elaboração dos autores.

A avaliação do estado nutricional do povoamento foi baseada em Silveira, Higashi e Moreira (2000), verificando-se que o enxofre e o ferro foram os nutrientes que as plantas apresentaram maior deficiência. Segundo Malavolta (1984), as causas de deficiência de enxofre, poderia estar relacionada aos teores baixos de matéria orgânica no solo e a alta relação C/S no solo o que dificulta a mineralização e, portanto o suprimento do elemento. Já os teores abaixo do adequado de Fe, estariam relacionados à inibição (antagonismo) provocada pelos teores elevados de Mn, o que faz com que a planta absorva menos ferro (MALAVOLTA, 1992).

Tabela 4. Teores de micronutrientes na biomassa de Eucalyptus urograndis aos 18 meses de idade, no município de Piratini-RS.

\begin{tabular}{cccccc}
\hline \multirow{2}{*}{ Componentes } & \multicolumn{5}{c}{ Micronutrientes $\left(\mathrm{mg} \mathrm{kg}^{-1}\right)$} \\
\cline { 2 - 6 } & $\mathrm{B}$ & $\mathrm{Cu}$ & $\mathrm{Fe}$ & $\mathrm{Mn}$ & $\mathrm{Zn}$ \\
\hline \multirow{2}{*}{ Madeira } & $5,07^{\mathrm{c}^{\mathrm{y}}}$ & $3,85^{\mathrm{c}}$ & $16,04^{\mathrm{b}}$ & $141,61^{\mathrm{c}}$ & $9,03^{\mathrm{b}}$ \\
& $( \pm 2,86)^{* *}$ & $( \pm 1,05)$ & $( \pm 7,72)$ & $( \pm 39,73)$ & $( \pm 6,75)$ \\
Casca & $23,99^{\mathrm{a}}$ & $3,89^{\mathrm{c}}$ & $29,15^{\mathrm{b}}$ & $1.615,45^{\mathrm{b}}$ & $9,48^{\mathrm{b}}$ \\
& $( \pm 5,05)$ & $( \pm 1,46)$ & $( \pm 7,81)$ & $( \pm 680,46)$ & $( \pm 2,59)$ \\
Galhos & $11,62^{\mathrm{b}}$ & $6,41^{\mathrm{b}}$ & $17,40^{\mathrm{b}}$ & $1.026,31^{\mathrm{b}}$ & $10,71^{\mathrm{b}}$ \\
& $( \pm 3,62)$ & $( \pm 1,11)$ & $( \pm 7,93)$ & $( \pm 440,40)$ & $( \pm 2,44)$ \\
& $27,78^{\mathrm{a}}$ & $10,26^{\mathrm{a}}$ & $50,81^{\mathrm{a}}$ & $2.532,56^{\mathrm{a}}$ & $17,83^{\mathrm{a}}$ \\
Folhas & $( \pm 6,64)$ & $( \pm 2,42)$ & $( \pm 5,57)$ & $( \pm 922,60)$ & $( \pm 2,74)$ \\
\hline CV (\%) & 60,74 & 49,69 & 58,06 & 79,89 & 43,85 \\
\hline
\end{tabular}

* Médias seguidas pela mesma letra na vertical, não diferem entre si pelo Teste de Tukey a 5\% de probabilidade de erro. **Valores entre parênteses, referem-se ao desvio padrão da média do nutriente em cada componente.

Fonte: Elaboração dos autores.

De um modo geral, com exceção do $\mathrm{Ca}, \mathrm{Mg}$ e $\mathrm{Cu}$ que estão mais armazenados nos galhos, a magnitude de armazenamento para os nutrientes nos componentes da biomassa segue a referida ordem: folhas $>$ galhos $>$ madeira $>$ casca (Tabelas 5 e 6 ). 
Tabela 5. Quantidade de macronutrientes na biomassa de Eucalyptus urograndis aos 18 meses de idade, no município de Piratini-RS.

\begin{tabular}{|c|c|c|c|c|c|c|}
\hline \multirow{2}{*}{ Componentes } & \multicolumn{6}{|c|}{ Macronutrientes $\left(\mathrm{kg} \mathrm{ha}^{-1}\right)$} \\
\hline & $\mathrm{N}$ & $\mathrm{P}$ & $\mathrm{K}$ & $\mathrm{Ca}$ & $\mathrm{Mg}$ & $\mathrm{S}$ \\
\hline Madeira & $\begin{array}{c}14,97 \\
(9,81)^{*}\end{array}$ & $\begin{array}{c}2,01 \\
(15,79)\end{array}$ & $\begin{array}{c}24,51 \\
(21,27)\end{array}$ & $\begin{array}{l}13,82 \\
(8,14)\end{array}$ & $\begin{array}{c}3,17 \\
(11,20)\end{array}$ & $\begin{array}{c}1,50 \\
(17,67)\end{array}$ \\
\hline Casca & $\begin{array}{c}6,39 \\
(4,19)\end{array}$ & $\begin{array}{c}0,78 \\
(6,14)\end{array}$ & $\begin{array}{c}9,71 \\
(8,43)\end{array}$ & $\begin{array}{c}29,06 \\
(17,12)\end{array}$ & $\begin{array}{c}3,91 \\
(13,80)\end{array}$ & $\begin{array}{c}0,44 \\
(5,23)\end{array}$ \\
\hline Galhos & $\begin{array}{c}23,98 \\
(15,72)\end{array}$ & $\begin{array}{c}3,19 \\
(25,07)\end{array}$ & $\begin{array}{c}36,98 \\
(32,10)\end{array}$ & $\begin{array}{c}87,14 \\
(51,33)\end{array}$ & $\begin{array}{c}11,05 \\
(39,02)\end{array}$ & $\begin{array}{c}1,67 \\
(19,62)\end{array}$ \\
\hline Folhas & $\begin{array}{r}107,19 \\
(70,28) \\
\end{array}$ & $\begin{array}{c}6,75 \\
(53,00) \\
\end{array}$ & $\begin{array}{c}44,00 \\
(38,19) \\
\end{array}$ & $\begin{array}{c}39,73 \\
(23,41) \\
\end{array}$ & $\begin{array}{c}10,19 \\
(35,98) \\
\end{array}$ & $\begin{array}{c}4,89 \\
(57,48) \\
\end{array}$ \\
\hline TOTAL & $\begin{array}{c}152,53 \\
(100,00)\end{array}$ & $\begin{array}{c}12,73 \\
(100,00)\end{array}$ & $\begin{array}{c}115,20 \\
(100,00)\end{array}$ & $\begin{array}{c}169,76 \\
(100,00)\end{array}$ & $\begin{array}{c}28,31 \\
(100,00)\end{array}$ & $\begin{array}{c}8,51 \\
(100,00)\end{array}$ \\
\hline
\end{tabular}

* Valores entre parênteses, referem-se à porcentagem que cada componente da biomassa possui de determinado macronutriente em relação ao seu total na biomassa.

Fonte: Elaboração dos autores.

Tabela 6. Quantidade de micronutrientes na biomassa de Eucalyptus urograndis aos 18 meses de idade, no município de Piratini-RS.

\begin{tabular}{cccccc}
\hline \multirow{2}{*}{ Componentes } & \multicolumn{5}{c}{ Micronutrientes $\left(\mathrm{g} \mathrm{ha}^{-1}\right)$} \\
\cline { 2 - 6 } & $\mathrm{B}$ & $\mathrm{Cu}$ & $\mathrm{Fe}$ & $\mathrm{Mn}$ & $\mathrm{Zn}$ \\
\hline \multirow{2}{*}{ Madeira } & 35,95 & 25,12 & 141,86 & 941,01 & 54,68 \\
& $(14,05)^{*}$ & $(24,01)$ & $(30,31)$ & $(5,63)$ & $(27,26)$ \\
\multirow{2}{*}{ Casca } & 33,24 & 4,98 & 38,68 & 2232,40 & 12,90 \\
& $(12,99)$ & $(4,76)$ & $(8,26)$ & $(13,35)$ & $(6,43)$ \\
\multirow{2}{*}{ Galhos } & 78,87 & 37,63 & 101,97 & 5230,86 & 63,69 \\
& $(30,82)$ & $(35,96)$ & $(21,79)$ & $(31,28)$ & $(31,75)$ \\
\multirow{2}{*}{ Folhas } & 107,83 & 36,91 & 185,54 & 8318,53 & 69,35 \\
& $(42,14)$ & $(35,27)$ & $(39,64)$ & $(49,74)$ & $(34,57)$ \\
\hline \multirow{2}{*}{ TOTAL } & 255,89 & 104,64 & 468,05 & $16.722,79$ & 200,62 \\
& $(100,00)$ & $(100,00)$ & $(100,00)$ & $(100,00)$ & $(100,00)$ \\
\hline
\end{tabular}

* Valores entre parênteses, referem-se à porcentagem que cada componente da biomassa possui de determinado micronutriente em relação ao seu total na biomassa.

Fonte: Elaboração dos autores.

A magnitude de armazenamento dos diferentes elementos na biomassa total apresentou a seguinte ordem decrescente de acúmulo para os macronutrientes: $\mathrm{Ca}>\mathrm{N}>\mathrm{K}>\mathrm{Mg}>\mathrm{P}>\mathrm{S}$ e $\mathrm{Mn}>$ $\mathrm{Fe}>\mathrm{B}>\mathrm{Zn}>\mathrm{Cu}$, para os micronutrientes.

A seqüência observada foi igual a verificada por Freitas (2000) com Eucalyptus grandis, aos nove anos de idade e Schumacher e Caldeira (2001) com Eucalyptus globulus subespécie maidenii aos quatro anos de idade. Santana, Barros e Neves (1999) e Teixeira et al. (1989) estudando povoamentos diferentes de Eucalyptus saligna e E. grandis, respectivamente, encontraram a mesma tendência do presente estudo em relação a acumulação de macronutrientes nos componentes formadores da biomassa aérea.

Estudando povoamentos de E. grandis, em duas áreas com diferentes produtividades, Reis, Barros e Kimmins (1987) encontraram para plantios com 15 meses de idade a seguinte magnitude de 
armazenamento: $\mathrm{N}>\mathrm{K}>\mathrm{Ca}>\mathrm{Mg}>\mathrm{P}$, diferindo para o povoamento com 21 meses $(\mathrm{N}>\mathrm{Ca}>\mathrm{K}>$ $\mathrm{Mg}>\mathrm{P})$.

\section{Conclusões}

A maior biomassa acima do solo esta no compartimento madeira.

As folhas apresentaram as maiores concentrações de nutrientes, sendo estatisticamente superior às demais frações $(p<0,05)$, com exceção ao $\mathrm{Ca}, \mathrm{Mg}$ e B.

A maior quantidade de nutrientes está contida no componente folhas, com exceção ao $\mathrm{Ca}, \mathrm{Mg}$ e $\mathrm{Cu}$ que estão alocados em maior quantidade nos galhos.

A magnitude total da quantidade de nutrientes na biomassa foi: $\mathrm{Ca}>\mathrm{N}>\mathrm{K}>\mathrm{Mg}>\mathrm{P}>\mathrm{S}$, para os macronutrientes e $\mathrm{Mn}>\mathrm{Fe}>\mathrm{B}>\mathrm{Zn}>\mathrm{Cu}$, para os micronutrientes.

\section{Agradecimentos}

Os autores agradecem a empresa Fibria Unidade Rio Grande do Sul pela disponibilização das áreas para estudo no município de Piratini e pelo apoio logístico e financeiro.

\section{Referências}

ABECEL. Cultura do eucalipto pela indústria brasileira exportadora de celulose. Rio de Janeiro: Associação Brasileira de Exportadores de Celulose, 2004, 16 p.

ANDRAE, F.; KRAPFENBAUER, A. Untersuchungen ueber Biomassen un Naehrstoffverhaeltnisse in einer 4-jaehrigen Aufforstung mit Eucalyptus saligna Smith in Santa Maria, RS - Brasilien. Centralblatt Fuerdas Gesamte Fostwesen, Vienna, v. 96, n. 1, p. 1-29, 1979.

BELLOTE, A. F. J. Concentração, acúmulo e exportação de nutrientes pelo Eucalyptus grandis em função da idade. 1979. Dissertação (Mestrado em Engenharia Florestal) - Escola Superior de Agricultura Luiz de Queiroz. Universidade de São Paulo, Piracicaba.

CALDEIRA, M. V. W.; VITORINO, M. D.; SCHAADT, S. S.; MORAES, E.; BALBINOT, R. Quantificação de serapilheira e de nutrientes em uma Floresta Ombrófila Densa Semina: Ciências Agrárias, Londrina, v. 29, n. 1, p. 53-68, 2008.

FERRI, M. G. Fisiologia vegetal 1. 2. ed. São Paulo: EPU, 1985. 362 p.

FREITAS, R. A. Estudo da biomassa e do conteúdo de nutrientes em um povoamento de Eucalyptus grandis Hill ex Maiden plantado em solo sujeito à arenização no município de Alegrete - RS. 2000. Dissertação (Mestrado em Engenharia Florestal) - Universidade Federal de Santa Maria, Santa Maria.

HASSE, G. Eucalipto: histórias de um imigrante vegetal. Porto Alegre: Já Editores, 2006. 127 p.

LA TORRACA, S. M.; HAAG, H. P.; MIGLIORINI, A. J. Recrutamento e exportação de nutrientes por Pinus elliottii var. elliottii em latossolo vermelho escuro na região de Agudos, SP. IPEF, Piracicaba, v. 27, n. 27, p. 41-47, 1984.

MALAVOLTA, E. ABC da análise de solos e folhas: amostragem, interpretação e sugestões de adubação. São Paulo: Editora Agronômica Ceres, 1992. 124 p.

. Absorção e transporte de íons e nutrição mineral. In: FERRI, M. G. Fisiologia vegetal 1. São Paulo: EPU, 1985. p. 77-116.

. Efeitos de doses e fontes de enxofre em culturas de interesse econômico. São Paulo: Centro de Pesquisa e Promoção de Sulfato de Amônio, 1984. 60 p. (Divulgação técnica; Boletim técnico, 3).

MOREnO, J. A. Clima do Rio Grande do Sul. Porto Alegre: Secretaria da Agricultura, 1961. 41 p.

PEREIRA, A. P.; ANDRADE, D. C.; LEAL, P. G. L.; TEIXEIRA, N. C. S. Produção de biomassa e remoção de nutrientes em povoamentos de Eucalyptus citriodora e Eucalyptus saligna cultivados na região de cerrado de Minas Gerais. Floresta, Curitiba, v. 15, n. 1, p.1 8-26, 1984.

PEREIRA, J.C.; CALDEIRA,M.V.W.; SCHUMACHER, M. V.; HOPPE, J. M.; SANTOS, E. M. Estimativa de conteúdo de nutrientes em um povoamento de Acacia mearnsii no Rio Grande do Sul - Brasil. Revista Árvore, Viçosa, v. 24, n. 2, p. 193-199, 2000.

POGGIANI, F.; COUTO, H. T. Z.; CORRADINI, L.; FAZZUO, E. C. M. Exploração de biomassa e nutrientes através da exportação dos troncos e das copas de um povoamento de Eucalyptus saligna. IPEF, Piracicaba, v. 25, n. 25, p. 37-39, 1983.

RAMBO, S. J. B. A fisionomia do Rio Grande do Sul. 3. ed. São Leopoldo: Ed. São Leopoldo, RS: UNISINOS, 2005. $473 \mathrm{p}$. 
REIS, M. G. F.; KIMMINS, J. P.; RESENDE, G. C.; BARROS, N. F. Acúmulo de biomassa em uma sequência de idade de Eucalyptus grandis plantado no Cerrado, em duas áreas com diferentes produtividades. Revista Árvore, Viçosa, v. 9, n. 2, p. 149-162, 1985.

REIS, M. G. F.; BARROS, N. F. Ciclagem de nutrientes em plantios de eucalipto. In BARROS, N. F.; NOVAIS, R. F. (Ed.). Relação solo-eucalipto. Viçosa: Folha de Viçosa, 1990. p. 265-301.

REIS, M. G. F.; BARROS, N. F.; KIMMINS, J. P. Acúmulo de nutrientes em uma sequência de idade de Eucalyptus grandis W. Hill (ex-Maiden) plantado no Cerrado, em duas áreas com diferentes produtividades, em Minas Gerais. Revista Árvore, Viçosa, v. 11, n. 1, p. 1-15, 1987.

SANTANA, R. C.; BARROS, N. F.; NEVES, J. C. L. Biomassa e conteúdo de nutrientes de procedências de Eucalyptus grandis e Eucalyptus saligna em alguns sítios florestais do estado de São Paulo. IPEF, Piracicaba,v. 56, n. 56, p. $155-169,1999$.

SCHUMACHER, M. V. Aspectos da ciclagem de nutrientes e do microclima em talhões de Eucalyptus camaldulensis Dehnh, Eucalyptus grandis Hill ex Maiden e Eucalyptus torelliana F. Messel. 1992. Dissertação (Mestrado em Ciências Florestais) - Escola Superior de Agricultura Luiz de Queiroz. Universidade de São Paulo, Piracicaba.

SCHUMACHER, M. V.; CALDEIRA, M. V. W. Quantificação de biomassa em povoamentos de Eucalyptus saligna Sm. com diferentes idades. Biomassa \& Energia, Viçosa, v. 1, n. 4, p. 381-391, 2004.

Estimativa da biomassa e do conteúdo de nutrientes de um povoamento de Eucalyptus globulus (Labillardière) sub-espécie maidenii. Ciência Florestal, Santa Maria, v. 11, n. 1, p. 45-53, 2001.

SCHUMACHER, M. V.; POGGIANI, F. Produção de biomassa e remoção de nutrientes em povoamentos de Eucalyptus camaldulensis Dehnh., Eucalyptus grandis ex Maiden e Eucalyptus torelliana F. Muell, plantados em Anhembi, SP. Ciência Florestal, Santa Maria, v. 3, n. 1, p. 21-34, dez. 1993.

SILVA, F. de A. S. ASSISTAT versão 7.5 beta. Campina Grande, PB: DEAG: CTRN: Universidade Federal de Campina Grande Campus de Campina Grande, PB, 2008.

SILVA, J. C. Cresce presença do eucalipto no Brasil. Revista da Madeira, Curitiba, n. 92, p. 61-66, out. 2005.

SILVEIRA, R. L. V. de A.; HIGASHI, E. N.; MOREIRA. A. Avaliação do estado nutricional do Eucalyptus: diagnose visual, foliar e suas interpretações. In: GONÇALVES, J. L. M.; BENEDETTI, V. Nutrição e fertilização florestal. Piracicaba: IPEF, 2000. 427 p.

SOARES, C. P. B.; PAULA NETO, F.; SOUZA, A. L. Dendrometria e inventário florestal. Viçosa: UFV. 2006, $276 \mathrm{p}$.

STRECK, E. V.; KÄMPF, N.; DALMOLIN, R. S. D.; KLAMT, E.; NASCIMENTO, P. C.; SCHNEIDER, P.; GIASSON, E.; PINTO, L. F. S. Solos do Rio Grande do Sul. 2. ed. Porto Alegre: EMATER/RS, 2008. 222 p.

TEDESCO, M. J.; GIANELLO, C.; BISSANI, C. A.; BOHNEN, H.; VOLKWEISS, S. J. Análise de solo, plantas e outros materiais. Porto Alegre: Departamento de Solos, UFRGS. 1995, 118 p. (Boletim técnico, 5).

TEIXEIRA, J. L.; BARROS, N. F.; COSTA, L. M.; CAMPOS, J. C. C.; LEAL, P. G. Biomassa e conteúdo de nutrientes de duas espécies de eucalipto em diferentes ambientes do médio Rio Doce, MG. Revista Árvore, Viçosa, v. 13, n. 1, p. 34-50, 1989.

VIERA, M. Avaliação da biomassa e nutrientes em povoamentos de Eucalyptus saligna Sm. e Eucalyptus urograndis no município de Pinheiro Machado, RS. 2007. Relatório (Estágio Supervisionado em Engenharia Florestal) - Universidade Federal de Santa Maria, Santa Maria. 